\title{
Teaching safety: evaluation of a children's village in Maryland
}

\author{
Andrea Carlson Gielen, Andrew L Dannenberg, Nancy Ashburn, Jingyee Kou
}

\begin{abstract}
Objectives - The purpose of this study was to evaluate Children's Village, a life safety education facility for children.
\end{abstract}

Setting-The study took place in Washington County, Maryland, a rural county.

Methods-Eight elementary schools with 20 second grade classrooms (410 students aged 7 and 8) were selected to participate. Using a quasiexperimental design, tests were administered to two cohorts of children before (pretest) and after (post-test) they attended the Children's Village during 1993-4. Parent and teacher surveys were also completed after the program.

Results-Among children who attended in December 1993-January 1994, there was a significant improvement in average test scores between the pretest $(58 \%$ correct) and post-test (78\%). Among children who attended in April 1994, there also was a significant improvement in test scores between pretest $(74 \%)$ and posttest $(85 \%)$. Among parents, $70 \%$ reported that their child learned a great deal at Children's Village and $33 \%$ reported having made changes in their home as a result. The parent survey also revealed that $25 \%$ of children and $35 \%$ of adults did not always wear their seat belts, and $74 \%$ of children did not always wear bicycle helmets. Teachers' responses to the program were generally positive.

Conclusions-Children's Village brought together an extensive network of community leaders, parents, and teachers dedicated to safety education of children. The curriculum had a positive impact on children's knowledge and, to a lesser extent, on parents' safety practices. Program impact could be enhanced by more emphasis on automobile restraints and helmets (behaviors that parents reported were not consistently practiced) and by expanding the village services to parents as well as children. Others considering creating similar programs need to identify community leaders willing to commit the time, effort, and resources required to develop and sustain such programs.

(Injury Prevention 1996; 2: 26-31)

Keywords: program evaluation, safety village, knowledge acquisition, behavior change.

For the school age population, injuries represent the leading cause of death. ${ }^{1}$ In the US, approximately 14 million children under 15 years of age are injured annually. ${ }^{2}$ The most common causes of injuries in this age group are motor vehicle related (including pedestrians), fire and burns, poisonings, and fall injuries. ${ }^{2}$ Prevention efforts have been directed toward parents and/or environmental modifications (for example, installing a smoke detector; putting energy absorbing materials under playground equipment) as well as toward teaching safety to children (for example street crossing skills).

There are a wide variety of curricular materials on various safety topics available for classroom teachers, ${ }^{3-5}$ although we could find only limited data evaluating their effectiveness. Most evaluated programs appear to be in the area of pedestrian skills. ${ }^{6-10}$ These include a broad array of educational approaches, such as individual instruction, audiovisual materials, behavior modification techniques, modeling, simulations, training in real street situations, and mass media campaigns. The evaluations suggest that: (1) educational approaches can increase children's knowledge of pedestrian safety; (2) training in real street situations has potential for changing unsafe behaviors; and (3) a parent education component is needed to maximize success.

In other injury areas, Richards et al found that a curriculum addressing spinal cord injury prevention significantly increased elementary schoolchildren's knowledge, but did not change their seat belt use. ${ }^{4}$ McLoughlin et al evaluated a curriculum to teach burn prevention to students in the Boston area. ${ }^{11}$ Although they found significant effects on students' knowledge of burn safety, they did not assess behavior change. In contrast, a recent evaluation of the 'Learn Not to Burn' curriculum in North Carolina found no detectable impact on children's knowledge of prevention strategies. ${ }^{5}$ More successful, however, are programs that teach preschool and elementary children when and how to dial 911 for emergencies. ${ }^{1213}$

Community life safety centers are an alternative or supplement to classroom instruction in safety. These facilities are child sized models of communities, with streets, traffic lights, and buildings where children receive instruction and practice skills under the guidance of police officers and fire fighters. A variety of topics can be taught, such as pedestrian skills, dialing the 911 emergency operator, use of medications, and fire safety. There have been no published evaluations of the effectiveness of such centers. The purpose of this paper is to present results from an evaluation of one such facility, Children's Village, in Hagerstown, the county seat of Washington County, Maryland. 
The Children's Village Advisory Committee (made up of representatives from the county council, school system, health department, fire department, and police department) invited the authors to evaluate the program's effectiveness and to identify ways in which it could be strengthened. The specific purposes of the evaluation were to determine: (1) whether, and to what extent, learning objectives for the children were achieved and maintained over time; (2) parents' reactions to their children's experience at Children's Village, and whether they made any changes in their home as a result; and (3) feedback from teachers on the Children's Village experience.

\section{Methods}

CHILDREN'S VILLAGE PROGRAM

Washington County is a rural county in western Maryland, with a population of 125480 of which 19950 are school age children. ${ }^{14}$ The village consists of an instructional building with office space, model roadways and businesses, with traffic lights and signs, and an actual home destroyed by fire. Most of the village was constructed between 1989 and 1991. Start up costs were estimated to be $\$ 800000$ (US). The actual cash outlay was held to $\$ 100000$ by using in-kind donations of land, labor, equipment, and supplies from the board of education, local contractors, and community service clubs. The yearly operating budget is $\$ 40000$, plus salaries for a full time executive director and administrative assistant. Funding is provided by local government and community donations. Instructors from the local fire and police departments donate an average of one day per month.

As part of the county's school curriculum, all second grade classes (7-8 year olds) visit the Children's Village. The village curriculum includes two days of activities: classroom teaching and educational videotapes, hands-on models and simulations, a walk-through of the home destroyed by fire, and use of child size, battery operated vehicles to drive through the model village. One full day is devoted to instruction on fire safety and one day on law enforcement related safety. Material included in the curriculum reflects the safety interests of the advisory panel for the village, which includes local administrative and classroom educators, public health professionals, com-

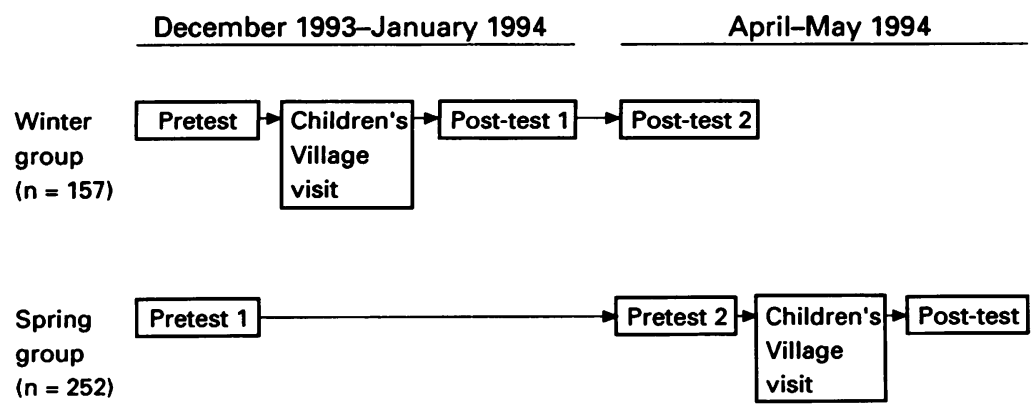

Children's Village evaluation design and study groups. munity members, police and fire officials, and the volunteer instructors.

Children are sent home with printed materials on fire safety for their parents. Parents are offered assistance in obtaining a smoke detector and are given a homework assignment to test smoke detectors, conduct a fire safety home audit, and develop a home fire escape plan.

\section{EVALUATION DESIGN}

A quasiexperimental design was used in which two cohorts of children attending Children's Village during the 1993-4 academic year were evaluated (figure). The winter group were children who attended Children's Village in December 1993 and January 1994; the spring group were children who attended in April 1994.

To assess both immediate and delayed effects of the program, the winter group received a test immediately before attending Children's Village (pretest), a test immediately after attending (post-test), and a second post-test four months later. To assess any maturation effect among second graders that may occur naturally over the course of the academic year, the spring group received an early pretest (at the same time as the pretest for the winter group), a second pretest immediately before attending Children's Village, and a post-test immediately after attending.

\section{SAMPLING}

Eight Washington County elementary schools with a total of 20 second grade classrooms were selected to participate. The selection was based on: (1) the need for an adequate sample size within each cohort; (2) the schedule of schools attending Children's Village; and (3) the schools' geographic locations, to adequately represent both the rural and urban/suburban areas of the county. Within each selected school, all second grade students present on the day the first pretest was administered were included in the sample $(n=410)$.

\section{INSTRUMENTS}

The instructors and advisory committee identified the curriculum's key concepts and learning objectives, which were then used as the basis for constructing the questionnaire items.

For burn prevention, students were expected to know the following: (1) in a fire, smoke rises and one should crawl low; (2) when and how to check smoke detector batteries; (3) how to put out a fire on the stove; (4) the importance of developing and practicing a fire escape plan; (5) how to 'stop, drop, and roll'; (6) in a fire, not to open a door if it is hot to the touch; and (7) where it is safe to put a space heater.

For life safety skills, students were expected to: (1) identify dangerous objects they might find around the house; (2) identify street signs that indicate a hazard; (3) identify where it is safe to cross a street; (4) identify dangerous play 
around water; and (5) know that they should wear a life jacket in a boat.

For law enforcement related content, students were expected to: (1) identify the types of help a police officer could provide; (2) define a 'stranger'; (3) know what to do if a stranger asks them to do something; (4) know what to tell a 911 emergency operator; (5) know they must wear a seat belt in a car; and (6) identify safe bicycle riding practices.

The pretest questionnaire was pilot tested with 38 second graders who had not yet attended the Children's Village and who would not be in the final sample. Based on results from this pilot, and input from the committee, revisions were made and a final version produced (available from the authors). The final instrument contained a combination of types of items, some of which asked students to circle correct responses that were either written words or illustrations, and some of which required them to write in the correct answers.

Although parents did not attend the Children's Village with their children, we wanted to determine the extent to which: (1) parents thought the visit was a useful experience for their children; (2) parents made changes in home safety practices after their children attended the Children's Village; and (3) there were unmet needs that the Children's Village could address in the future. A questionnaire with a stamped, return envelope was sent home with the children on the day the first post-test was administered in the classroom. A reminder postcard was sent approximately one week later.

Feedback on the program was also obtained from the participating teachers. A questionnaire was sent at the end of the school year to all teachers in the eight schools. Five open ended items were used to assess the strengths and weaknesses of the Children's Village curriculum and to obtain suggestions for changes in the program.

The study protocol was reviewed and approved by the Committee on Human Research at the Johns Hopkins University School of Public Health.

\section{DATA ANALYSES}

The pretests and post-tests were graded and per cent correct scores used for analyses.

Table 1 Comparison of mean change scores between pretest and post-test by study group. Children's Village evaluation, students ages 7-8, Washington County, Maryland, 1993-4

\begin{tabular}{|c|c|c|c|c|}
\hline & $\begin{array}{l}\text { Mean } \% \\
\text { correct }(S D)\end{array}$ & $\begin{array}{l}\text { Paired } \\
\mathrm{t} \text { test }\end{array}$ & $\begin{array}{l}\text { Significance } \\
\text { (p value) }\end{array}$ & $\begin{array}{l}\text { No of } \\
\text { children }\end{array}$ \\
\hline $\begin{array}{l}\text { Winter group } \\
\text { Pretest } \\
\text { Post-test } 1\end{array}$ & $\begin{array}{l}58 \cdot 2(1 \cdot 2) \\
77 \cdot 5(1 \cdot 0)\end{array}$ & $16 \cdot 80$ & $<0.001$ & 135 \\
\hline $\begin{array}{l}\text { Post-test } 1 \\
\text { Post-test } 2\end{array}$ & $\begin{array}{l}77.9(1.0) \\
79.1(0.9)\end{array}$ & $1 \cdot 15$ & NS & 123 \\
\hline $\begin{array}{l}\text { Spring group } \\
\text { Pretest } 2 \\
\text { Post-test }\end{array}$ & $\begin{array}{l}73.9(0.9) \\
84.7(0.8)\end{array}$ & $14 \cdot 20$ & $<0.001$ & 146 \\
\hline $\begin{array}{l}\text { Pretest } 1 \\
\text { Pretest } 2\end{array}$ & $\begin{array}{l}66.9(1.0) \\
73.7(0.9)\end{array}$ & $7 \cdot 68$ & $<0.001$ & 115 \\
\hline
\end{tabular}

Criteria for judging a correct response were developed by the investigators in consultation with the advisory committee. Pretest and posttest forms were matched by student initials, and prepost difference scores were calculated for each student. Paired $t$ tests were used to compare mean differences between pretests and post-tests. To examine in more detail those items on which students showed the most improvement, we also present the frequency of responses to each item.

\section{Results}

\section{STUDENTS}

Four hundred and ten children (158 in the winter group and 252 in the spring group) participated, equally divided between boys and girls. Schools in the winter group had a higher proportion of students receiving state subsidized free meals (an indicator of socioeconomic status) and lower scores on standardized tests than schools in the spring group. Students in the winter group also had lower scores than the spring group on the first pretest for this study $(58 \% v 67 \%$ correct $)$ (table 1).

In the winter group, data were available for before and after comparisons for 135 students for four schools. * There was a significant improvement in test scores between the pretest $(58 \%)$ and the first post-test $(78 \%)$, and scores remained high $(79 \%)$ on the second post-test (table 1). For analysis of the spring group, data were available for 146 students from three schools. $\uparrow$ The average scores for students in the spring group increased significantly from the first to second pretest $(67 \%$ to $74 \%)$ in the absence of any intervention, which suggests a maturation effect over the four month interval. None the less, scores did increase significantly after the intervention $(74 \%$ to $85 \%$ ) (table 1$)$. Findings for both the winter and spring groups remained the same when the data were analyzed for each school separately, with only two exceptions: in one school, scores improved significantly from the first to second post-test; and in another school, scores did not change from first to second pretests.

Responses to the individual questionnaire items are presented in table 2 . There was great variability in the frequency of correct responses, although virtually all items showed improvement. For some items, students' knowledge was quite high at the outset (for example dangerous items; stop, drop, and roll; life jackets; and bicycle safety). Conversely, for others, knowledge remained low on the posttest (for example practicing a fire escape plan; placement of heaters; what to tell the 911 emergency operator; medicines as dangerous items; what to do if a stranger approaches). For the remainder, $70 \%$ or more of all students answered correctly on the post-test.

^Twenty three students not completing the post-test were eliminated; their mean pretest score was $53 \%$

One spring group school did not complete the second pretest due to administrative problems. Eight students who did not complete the post-test were eliminated; their mean score on the second pretest was $71 \%$ 
Table 2 Per cent correct response to each questionnaire item by study group. Children's Village evaluation, students ages 7-8, Washington County, Maryland, 1993-4

\begin{tabular}{|c|c|c|c|c|}
\hline \multirow[b]{2}{*}{ Questions } & \multicolumn{2}{|c|}{ Winter group } & \multicolumn{2}{|c|}{ Spring group } \\
\hline & $\begin{array}{l}\text { Pretest } \\
(n=158)\end{array}$ & $\begin{array}{l}\text { Post-test } 1 \\
(n=154)\end{array}$ & $\begin{array}{l}\text { Pretest } 2 \\
(n=154)\end{array}$ & $\begin{array}{l}\text { Post-test } \\
(n=228)\end{array}$ \\
\hline $\begin{array}{l}\text { 1. Smoke goes up in a fire } \\
\text { 2. Crawl low in a fire } \\
\text { 3. How to check smoke detectors } \\
\text { 4. Stop, drop, roll } \\
\text { 5. Practice escape plan } \\
\text { 6. Don't open hot door } \\
\text { 7. Circle what could hurt: } \\
\text { A. Hot water } \\
\text { B. Matches } \\
\text { C. Saw } \\
\text { D. Gun } \\
\text { E. Lighter } \\
\text { F. Heater } \\
\text { G. Medicine } \\
\text { 8. Where to place heaters } \\
\text { 9. When to check smoke detectors } \\
\text { 10. How to put out fire } \\
\text { 11. Recognize signs: } \\
\text { A. 'Danger' } \\
\text { B. 'Caution' } \\
\text { C. 'Warning' } \\
\text { 12. What to tell } 911 \text { operator } \\
\text { 13. Safe play around water } \\
\text { 14. What police do } \\
\text { 15. Who is a stranger } \\
\text { 16. Where to cross a street } \\
\text { 17. What to do if stranger approaches } \\
\text { 18. Wear a seat belt } \\
\text { 19. Wear a life jacket } \\
\text { 20. Bike riding rules } \\
\text { 21. Happy faces circled }\end{array}$ & $\begin{array}{r}79 \\
97 \\
85 \\
94 \\
97 \\
75 \\
39 \\
6 \\
39 \\
14 \\
75 \\
47 \\
63 \\
6 \\
89 \\
39 \\
81 \\
56 \\
24 \\
73 \\
94 \\
89 \\
\text { NA }\end{array}$ & $\begin{array}{l}79^{\star \star \star} \\
70^{\star \star \star} \\
71^{\star \star \star} \\
97^{\star \star} \\
54^{\star \star \star} \\
71^{\star \star \star} \\
96^{\star \star \star} \\
97 \\
93^{\star} \\
99^{\star} \\
97 \\
90^{\star \star \star} \\
61^{\star \star \star} \\
29^{\star \star \star} \\
75^{\star \star \star} \\
77^{\star \star \star}\end{array}$ & $\begin{array}{l}71 \\
36 \\
47 \\
99 \\
47 \\
77 \\
95 \\
99 \\
91 \\
98 \\
99 \\
95 \\
80 \\
15 \\
34 \\
41\end{array}$ & $\begin{array}{l}86^{\star \star \star} \\
65^{\star \star \star} \\
71^{\star \star \star} \\
99^{\star \star \star} \\
66^{\star \star \star} \\
84 \\
97 \\
99 \\
92 \\
98 \\
99 \\
94 \\
84 \\
35^{\star \star \star} \\
70^{\star \star \star} \\
91^{\star \star \star} \\
94 \\
82^{\star} \\
89^{\star} \\
25 \\
94 \\
83 \\
87^{\star} \\
80^{\star} \\
78 \\
92 \\
98^{\star} \\
96^{\star} \\
91\end{array}$ \\
\hline
\end{tabular}

On the post-test to judge affective responses to the Children's Village, students were asked to circle the picture that described how they felt about their visit - a sad face, a neutral face, or a happy face. Over $90 \%$ of children circled the happy face.

\section{PARENTS}

Three hundred eighty one students were given a parent questionnaire when they completed the first post-test; 302 of these were returned $(79 \%)$. Seventy per cent of parents reported that their child learned 'a great deal' at the Children's Village and $38 \%$ reported that the parents themselves learned 'a great deal'. Ten per cent said their child was frightened by something at the Children's Village; most often this reflected fears about house fires.

One third of parents reported having made changes in their home as a result of their child's visit such as adding smoke detectors and/or batteries, putting 911 emergency stickers on telephones, talking with children about safety, practicing an escape plan.

With regard to potential unmet need, $25 \%$ of parents reported that their child did not always wear his/her seat belt and 35\% reported that they themselves did not always wear one. Seventy four per cent of the sample also reported that their child did not always wear a bicycle helmet, and $45 \%$ did not own one. Only $3 \%$ of parents stated that they did not have a smoke detector, although $16 \%$ did not have one on every floor. Thirty two per cent stated they checked their smoke detector yearly, 55\% monthly, and $6 \%$ weekly. Although $88 \%$ of parents had a fire escape plan, 50\% admitted they had never practiced it.
TEACHERS

Of the 20 teacher feedback forms mailed, 12 $(60 \%)$ were returned. Responses to the five open ended items were transcribed verbatim and summarized. In general, there were many positive comments - the enthusiasm and competence of the instructors, and the usefulness of hands-on experiences (for example riding in miniature cars, touring the burned house). Several respondents suggested that there should be additional hands-on and physically active components.

\section{Discussion}

The results of this evaluation indicate that the learning objectives of the Children's Village were achieved and maintained over the four month follow up period. The significant improvement in knowledge scores was evidenced in analyses of both the individual schools and the total winter group and spring group. That the intervention successfully increased knowledge is consistent with findings in pedestrian safety, ${ }^{8}$ spinal cord injury prevention, ${ }^{4}$ emergency responsiveness, ${ }^{1213}$ and burn prevention. ${ }^{11}$

The post-test scores among the entire sample, which ranged between $78 \%$ and $85 \%$, indicate relatively high levels of knowledge. Analysis of item specific responses suggest topics for which additional education may be needed. Most students did not know the correct placement of space heaters (away from curtains), most could not provide all of the correct information to the 911 emergency operator (location, telephone number, problem), and few reported having practiced a fire escape plan at home. The question about 911 telephone calls required students to write all three correct responses; thus, the low scores on this item may reflect inadequate writing skills rather than lack of knowledge about what to tell the operator. Practicing an escape plan depends on parents' participation, suggesting that more effort be directed toward parents.

These results must be interpreted within the limitations of the study. It was not possible to randomly assign children to intervention and control groups because the program is part of the county curriculum for all second grade children. The difference between the two cohorts in baseline knowledge (the spring group had higher pretest scores than the winter group) was most likely due to the higher socioeconomic status of families in the spring group. This difference at baseline makes it difficult to use the spring group to examine whether improvements in the winter group were the result of maturation or the intervention. The improvement in the spring group from the first to second pretest ( 7 percentage points) suggests some maturation effect; however, this increase is substantially less than the improvement before and after attendance in the winter group (20 percentage points). The spring group's average score increased significantly (11 percentage points) after their visit, further strengthening the conclusion that the visit had an impact on children's 
knowledge, beyond any effects of maturation and testing. Without a post-test only comparison group, however, testing effects cannot be ruled out for either cohort. That the cohorts differed in pre-existing knowledge and abilities at baseline and over the course of the academic year, suggests that program effectiveness might be enhanced by more tailoring of the curriculum to the learning needs of different groups of students.

Another limitation of the study is that we were unable to observe the use of specific skills (for example, street crossing behavior) or confirm self reported practices (for example, location of functioning smoke detectors in the home). Such outcome assessments were beyond the resources available for this project. The extent to which findings from observations in an experimental context are generalized to 'real life' injury risk situations has been questioned. ${ }^{710}$ Behavioral theories, ${ }^{15}$ as well as results from previous injury prevention studies, ${ }^{4810}$ suggest that it is inappropriate to expect knowledge gains to translate into broad scale, sustainable improvements in safety behaviors in the absence of any additional intervention (for example booster sessions). None the less, it is important to note that in the four and a half years since the Children's Village opened, there have been at least five reports of children who applied what they had learned there to emergency situations (two children who telephoned the 911 operator when their mother was injured, two who helped their baby sitters extinguish a fire, and one who saved herself and two brothers in a housefire)..$^{1617}$

Our findings with regard to parents are particularly noteworthy. Not only did $70 \%$ report that their child learned a great deal from the visit, one third also reported having made safety changes in their home. The majority of families reported having a smoke detector and checking it regularly. However, a substantial number had not practiced a fire escape plan and did not routinely use seat belts for themselves or their children. Moreover, many parents reported that their child neither owned nor used a bicycle helmet. Future efforts should capitalize on parents' favourable response to the program and target these injury prevention practices. Other programs have also noted the importance of involving parents to teach safety to children. ${ }^{718}$

The Children's Village brought together an extensive network of community leaders, parents, and teachers dedicated to safety education of children. The village can use the findings that children and parents benefitted in meaningful ways as support for expanding its services to more families. As a focal point in the county for childhood injury prevention, the program's impact could perhaps be enhanced by incorporating additional community based interventions. For example, the Children's Village could sponsor activities such as outreach to parents, bicycle helmet distributions, media campaigns, and advocacy for legislative or regulatory changes that promote children's safety.
The results of this evaluation suggest a number of advantages of such programs that may generalize to other communities. First, a village provides a distinct site for teaching all children in the county about important safety issues. Second, the program leads to demonstrable improvements in children's knowledge of specific safety issues. Third, some of the practical skills taught in a village could not be readily taught in the classroom. Fourth, the program facilitates communication between the county's school children and its fire and police departments. A safety village may be a more efficient means to foster such communication than sending fire or police officers into every classroom in the county. Finally, the results indicate that many parents make safety improvement in their homes in response to messages conveyed from the village by their children.

Communities considering replicating the Children's Village should also consider some possible disadvantages of this approach to teaching safety to children. First, neither the present study nor the published literature provide a clear answer to whether children have fewer injuries even after an educational program improves their knowledge and increases their safety skills. Second, the generalizability of our results must be considered in light of the enormous effort that went into this program on the part of key individuals in the county. Replicability will also depend on the extent to which other communities can generate similar widespread support and commitment of resources. Thus, communities considering the creation of a safety village should first examine existing villages in detail and should identify their own community leaders willing commit time, effort, and resources to the project. In all cases, project organizers are urged to incorporate an evaluation process into the development of the village to facilitate ongoing improvements. With adequate resources and time, it would be of substantial interest to observe safety practices and injury hazards, as well as to compare injury events and outcomes between communities with and without such programs.

This work was supported by grants from the Washington County Health Department and Maryland Department of Health and Mental Hygiene; and the Centers for Disease Health and Mental Hygiene; and the Centers for
Control and Prevention (grant No R49/CCR302486)

Control and Prevention (grant No R49/CCR302486) The authors gratefully acknowledge the support and assis-
tance provided by the Children's Village Advisory Committee, tance provided by the Children's Village Advisory Committee,
the Washington County Health Department, the Maryland the Washington County Health Department, the Maryland
Department of Health and Mental Hygiene, as well as the classroom teachers, students, and parents who participated in this evaluation.

1 Baker PB, O'Neill B, Ginsburg MJ, Li G. The injury fact book. 2nd Ed. New York, NY: Oxford University Press, 1992 .

2 Rice DP, Mackenzie EJ and Associates. A report to Congress. Cost of injury in the United States. San Francisco, CA: University of California and Baltimore, MD: John Hopkins University, 1989.

3 Race KEH. Evaluating pedestrian safety education materials for children aged five to nine. $\mathcal{F}$ Sch Health 1988; 58: $277-81$.

4 Richards JS, Hendricks $C$, Roberts $M$. Prevention of spinal cord injury: an elementary education approach. $\mathcal{F}$ Pediat cord injury: an elementary edu

5 Grant E, Turney E, Bartlett $M$, Winbon C, Peterson HD Burn prevention forum. Evaluation of a burn prevention program in a public school system. $\mathcal{F}$ Burn Care Rehabil 1992; 13: 703-7. 
6 Preusser DF, Blomberg RD. Reducing child pedestrian accidents through public education. $\mathcal{F}$ Safety Res 1984; 15: 47-56.

7 Rivara FP, Booth CL, Bergman AB, Rogers LW, Weiss J. Prevention of pedestrian injuries to children: effectiveness of a school training program. Pediatrics 1991; 88: 770-5.

8 Malek M, Guyer B, Lescohier I. The epidemiology and prevention of child pedestrian injury. Accid Anal Prev 1990; 22: 301-13.

9 Renaud L, Suissa S. Evaluation of the efficacy of simulation games in traffic safety education of kindergarten children. Am ₹ Public Health 1989; 79: 307-9.

10 Rothengatter JA. The influence of instructional variables on the effectiveness of traffic education. Accid Anal Prev 1981; 13: 241-53.

11 McLoughlin E, Vince CJ, Lee AM, Crawford JD. Project burn prevention: outcome and implications. Am $\mathcal{f}$ Public Health 1982; 72: 241-7.

12 Rosenbaum MS, Creedon DL, Drabman RS. Training preschool children to identify emergency situations and make emergency phone calls. Behav Ther 1981; 12: make em

13 Jones RT, Kazdin AE. Teaching children how and when to make emergency telephone calls. Behav Ther 1980; 11: 509-21

14 Maryland Department of Health and Mental Hygiene. Maryland vital statistics, 1992. Baltimore: Maryland Department of Health and Mental Hygiene, 1992.

15 Green LW, Kreuter MW. An educational and environmental approach. Health promotion planning. 2nd Ed. Mountain View, CA: Mayfield Publishers, 1991.

16 Sopp B. Teaching safety at Children's Village. Maryland EMS News 1994; 21(3): 1-2 (Dec).

17 Ford C. An act of faith: 8-year old uses training to lead brothers out of fire. Morning Herald (Hagerstown, Maryland). May 5, 1995: A1.

18 Perry CL, Luepker RV, Murray DM, et al. Parent involvement with children's health promotion: the Minnesota home team. Am ₹ Public Health 1988; 78: 1156-60.

\section{Editorial Board Member: brief biography}

\section{MICHAEL HAYES}

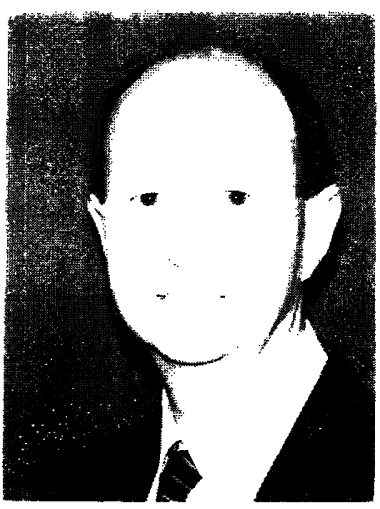

After graduating in physics at the University of Birmingham, Michael Hayes joined the University's Accident Research Unit. He was awarded his $\mathrm{PhD}$ following a study of traffic conflicts. Subsequently, as a member of the unit's staff, he was involved in an at-scene study that researched the relationship between vehicle design and pedestrian injuries. He then joined a team examining the crash performance of cars in real accidents, in the context of safety standards.

In the early 1980 s Dr Hayes was the researcher responsible for the collection of data for a major project which evaluated the effects on injuries of the seat belt law in the UK.

Currently, Dr Hayes is the Projects Director of the UK's leading charity involved solely in preventing accidents and injuries to children, the Child Accident Prevention Trust. His work includes the development and management of the trust's programme and information service.

His interest in traffic safety continues through his involvement in the British Standards Institution's technical committees for child restraints and cycle helmets. He is also a member of the UK delegation to the European standards committee that is writing the cycle helmet standard.

Dr Hayes is a founding member and treasurer of the International Society for Child and Adolescent Injury Prevention, and a member of the group advising on the scientific programme for the Third World Conference on Injury Prevention and Control.

Finally, Dr Hayes is a member of the UK government's Health of the Nation Accident Task Force, and its information and research subgroups. His longstanding interest in injury and accident data collection systems lead to his being invited to chair the committee that evaluated the Canadian Hospitals Injury Research and Prevention Programme (CHIRPP) for Health and Welfare Canada. 